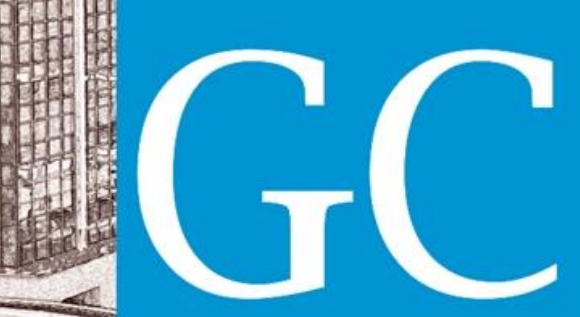

Revista Nacional de Gerenciamento de Cidades

\title{
Áreas de mananciais: desafios dos programas de intervenções urbanas em áreas protegidas da sub-bacia da Billings, São Bernardo do Campo
}

Management areas: challenges of urban intervention programs in protected areas of the Billings sub-basin, São Bernardo do Campo

Áreas de gestión: desafíos de los programas de intervención urbana en áreas protegidas de la sub-cuanca de Billings, São Bernardo do Campo

Jeane Aparecida Rombi de Godoy Rosin

Doutora em Arquitetura e Urbanismo;

Docente do Centro Universitário de Várzea Grande - UNIVAG.

urbanista.jeane@gmail.com 


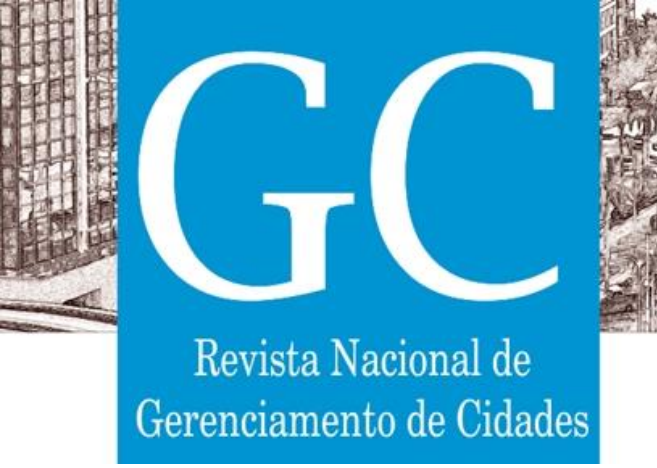

\section{RESUMEN}

Este documento aborda los desafíos de las intervenciones urbanas guiadas por la legislación actual para la protección de áreas de preservación permanente, áreas protegidas, especialmente aquellas implementadas en áreas de cuenca. Hoy, el porcentaje de ciudades brasileñas que presentan una paradoja entre su desarrollo físico y la sostenibilidad del entorno en el que operan es significativo. Debido a sus especificidades, las áreas de preservación permanente requieren cuidados intensivos e integrales, ya que su preservación y mantenimiento requieren acciones políticas que puedan intervenir de manera equilibrada entre el crecimiento urbano, la calidad de vida y la recuperación del medio ambiente natural. Desde esta perspectiva, la dimensión ambiental comenzó a incorporarse de manera transdisciplinaria, rescatando valores importantes en la formulación de una política de desarrollo urbano, basada en los principios de sostenibilidad. Por lo tanto, este artículo tiene como objetivo analizar los resultados de las políticas públicas recientes a través de un estudio de caso, desde planes hasta proyectos urbanos, observando las limitaciones y potencialidades contenidas en su alcance de referencia. Por lo tanto, las acciones resultantes de las políticas públicas en asentamientos de viviendas precarias ubicadas en áreas de PPA se analizarán a través de proyectos destinados a la restauración ambiental urbana en áreas protegidas de las fuentes: APRM de la presa Billings en São Bernardo do Campo. La elección de esta área se debió a los efectos nocivos resultantes de la precaria ocupación urbana identificada en áreas de cuencas hidrográficas, donde las autoridades estatales, municipales y públicas han intentado durante décadas implementar una serie de acciones, que culminaron en la elaboración de programas específicos dirigidos a Restauración socioambiental centrada en la integración urbana y terrestre. En resumen, las propuestas de intervenciones urbanas destinadas a la restauración urbana y ambiental de las APP en las fuentes públicas de agua, destinadas a la restauración social y ambiental para enfrentar sus divergencias, pueden desempeñar un papel crucial en la restauración de las múltiples funciones de la red de agua, en particular mediante el rescate del suministro de agua. servicios ecosistémicos esenciales, no solo para la sostenibilidad, sino también un camino necesario para la resiliencia de los espacios protegidos.

Palabras-clave: Áreas de cuenca. Áreas Protegidas Programas de intervención urbana. 


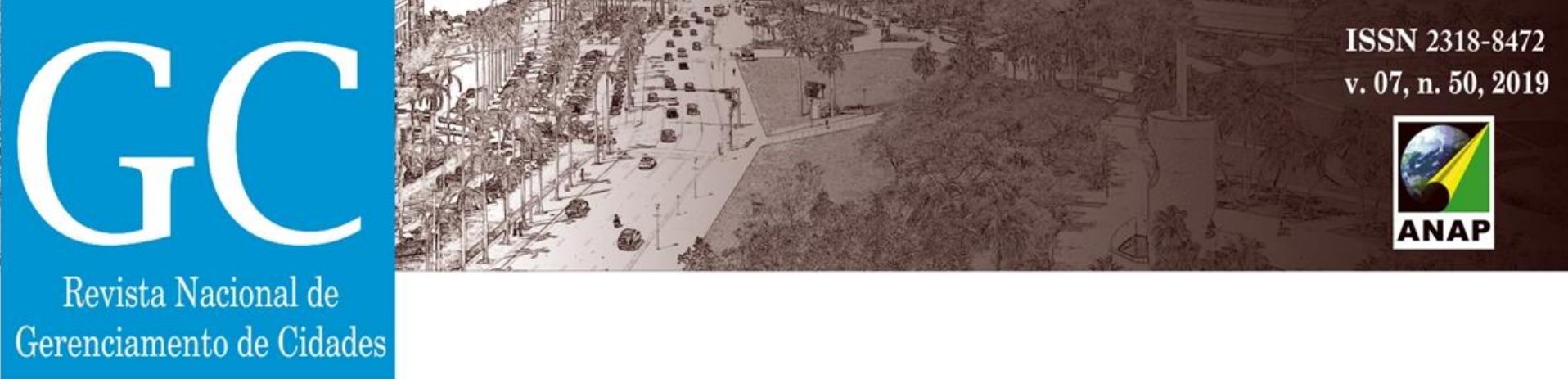

\section{INTRODUÇÃO}

Este estudo tem por intenção discutir alguns aspectos sobre a eficácia dos programas recentes de intervenções urbanas orientados pela atual legislação de proteção de áreas de preservação permanente, em especial, aqueles implementados em áreas de mananciais. No contexto atual da maioria das cidades brasileiras é possível identificar cenários que apresentam um paradoxo entre o seu desenvolvimento físico e a sustentabilidade do ambiente em que estão inseridas. Em razão de suas especificidades, as áreas protegidas, em especial as áreas de preservação permanente exigem cuidados intensos e abrangentes visto que sua preservação e manutenção não dependem apenas da conscientização da sociedade, mas também, de ações políticas que possam intervir de maneira equilibrada entre o crescimento urbano, a qualidade de vida e recuperação do meio natural. Partindose do pressuposto que as legislações urbanas e ambientais através de políticas públicas constituem mecanismos fundamentais para o seu desenvolvimento - notadamente ao prevenir e mitigar problemas socioambientais, as intervenções urbanas por meio de projetos urbanísticos não podem ser pensadas como ações rotineiras frente a mais um problema urbano - mas devem ser envolvidas em um universo ambiental onde o maior interesse seja o bem-estar humano. Na Região Metropolitana de São Paulo (RMSP), como também, em outras cidades brasileiras, a ocupação precária de áreas protegidas, em especial, áreas que abrigam os mananciais de abastecimento de água, exige uma atenção diferenciada nos processos de elaboração de políticas públicas dedicadas a seu enfrentamento, onde se verifica em uma vertente - a prioridade da preservação das áreas que abrigam os mananciais de água para abastecimento da população - em outra, a problemática habitacional, presente em áreas consolidadas que abrigam um contingente populacional significativo (ALVIM, 2014). Em caráter específico, as áreas de preservação permanente, delimitadas pelas bordas da Represa Billings - ocupadas por assentamentos habitacionais precários ocasionam diversos impactos negativos no manancial, os quais afetam não apenas a população residente, mas toda a metrópole ao intensificar as vulnerabilidades socioambientais. Neste contexto, com o propósito de minimizar os efeitos nocivos resultantes da ocupação urbana precária identificados em áreas de mananciais, o Estado, ao final da década de 70 promulgou a Legislação de Proteção dos Mananciais - LPM (Leis Estaduais n. ㅇ 898/75 e 1.172/76 e o Decreto Estadual no 9.714/77), entretanto, em pouco tempo, percebeu-se insuficiente para sanar toda a complexidade envolvida (ALVIM, 2010).

Em 1988, a Constituição Federal no rol dos novos direitos, também comtemplou o direito coletivo ao meio ambiente equilibrado e à gestão democrática das cidades, em especial, ao possibilitar atuações diferenciadas, a exemplo dos programas de urbanização e integração de assentamentos precários, por meio de ações institucionais e políticas locais.

Entretanto, após uma década, as ações governamentais voltadas a questão da ocupação das áreas de mananciais se mostraram incipientes e esparsas, não sendo observado qualquer tipo de recuperação, sobretudo, ambiental destes espaços (ALVIM,2014).

De modo surpreendente, houve um efeito inverso, com aumento significativo de loteamentos informais e clandestinos, bem como, um intenso processo de favelização de seu entorno, resultando 


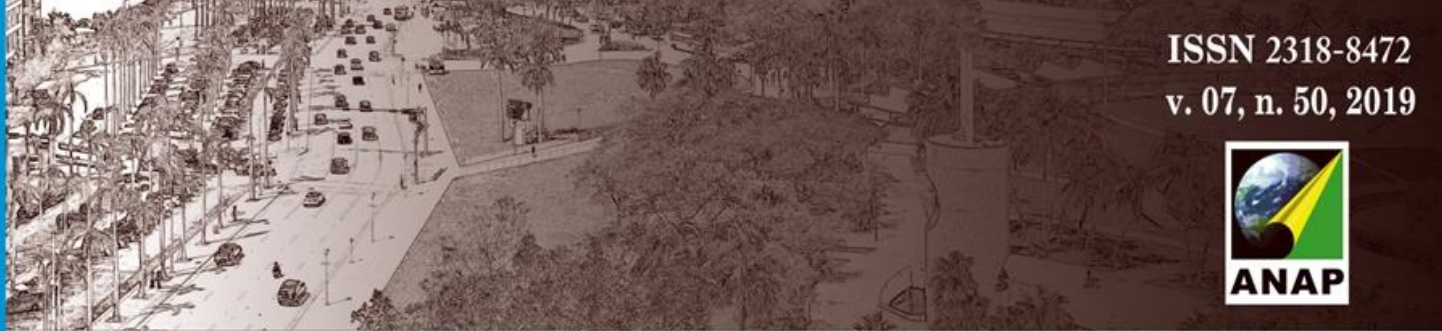

Revista Nacional de

Gerenciamento de Cidades

em altas taxas de desmatamento e degradação ambiental. Em resposta a essa conjuntura, o Poder Público deu início a uma série de ações, culminando na elaboração de programas específicos voltados à recuperação socioambiental com enfoque na integração urbanística e fundiária. Assim, em 1997, o Governo Estadual, por meio da Lei Estadual no 9.866, instituiu um novo modelo de planejamento e gestão dedicado ao tratamento específico das áreas de mananciais, onde não somente passou a adotar a bacia hidrográfica como unidade de intervenção, como também previu a adoção de instrumentos de caráter urbano-ambiental, visando à recuperação das áreas degradadas. Neste contexto, as sub-bacias Guarapiranga e Billings, ambas ao sul da região metropolitana de São Paulo, foram as primeiras a regulamentar a nova lei de mananciais a partir da aprovação de suas leis específicas - Lei Estadual no 12.233/06, Guarapiranga e Lei Estadual no 13.579/09 Billings, resultando na implementação de instrumentos urbanísticos e ambientais para recuperação de suas áreas degradadas (ALVIM, 2010). Em síntese, possibilitaram uma nova abordagem às políticas públicas urbanas, as quais foram materializadas nas propostas de intervenções urbanísticas destinadas a recuperação urbana e ambiental dos espaços afetados.

A partir desse contexto, foram eleitos para estudo de caso, projetos implantados em São Bernardo do Campo, em áreas de proteção e recuperação aos mananciais da represa Billings, como problema tipo, representativo de outras áreas degradadas com características semelhantes. Dessa forma, tentou despertar a atenção para a seriedade da questão e seu tratamento normativo por meio de novas possibilidades técnicas em respostas a efetiva recuperação ambiental dos mananciais. Desse modo, buscou-se uma ampliação da discussão acerca dos desafios e possibilidades de efetivação dos programas de intervenção urbana, em específico dos projetos de urbanização e integração de assentamentos precários em áreas de mananciais, em interface com os novos instrumentos ambientais em curso, definidos pela atual legislação de proteção e recuperação dos mananciais.

\section{ESTUDO DE CASO - SÃO BERNARDO DO CAMPO (SBC)}

No contexto das cidades brasileiras, em especial, no estado de São Paulo a cidade de São Bernardo do Campo ganha visibilidade não somente por seus atributos de riqueza, mas notadamente por configurar-se num dos cenários urbanos, onde as externalidades assumem dimensões inusitadas, em especial, ao tornar-se um epicentro de contradições. Essa configuração espacial articulada pelas rodovias Anchieta e Imigrantes e recentemente pelo Rodoanel, foram determinantes para seu processo de urbanização, garantindo uma posição notória na região metropolitana paulista (PMSBC, 2011).

O último censo realizado (IBGE, 2010), apontou que o município possui uma população de 765.203 hab., onde 752.417 hab. residem na área urbana e 12.786 hab. são residentes de áreas rurais. 

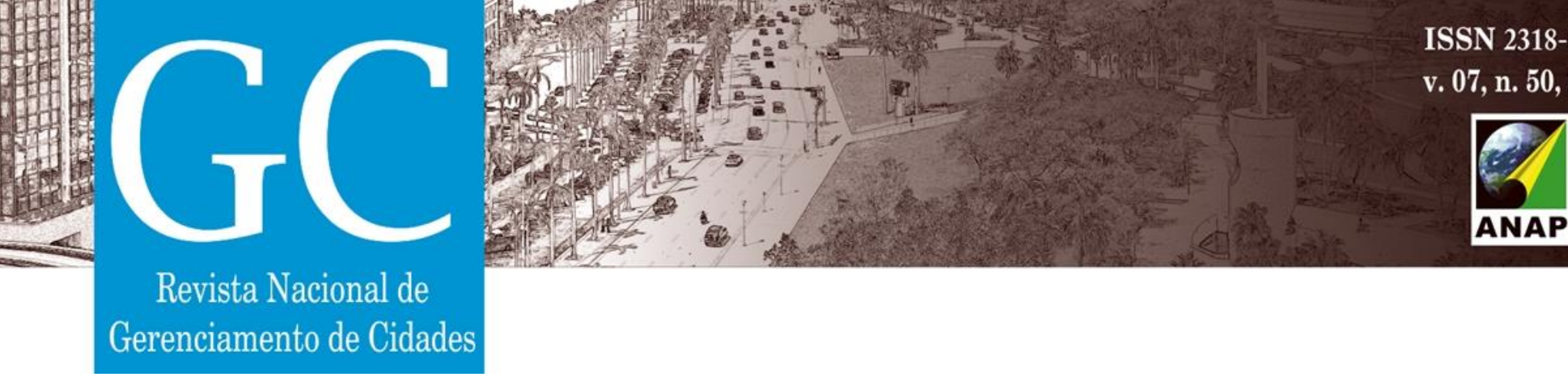

ANAP

Figura 1 - Projeção da Expansão da Mancha Urbana da RMSP em 2030

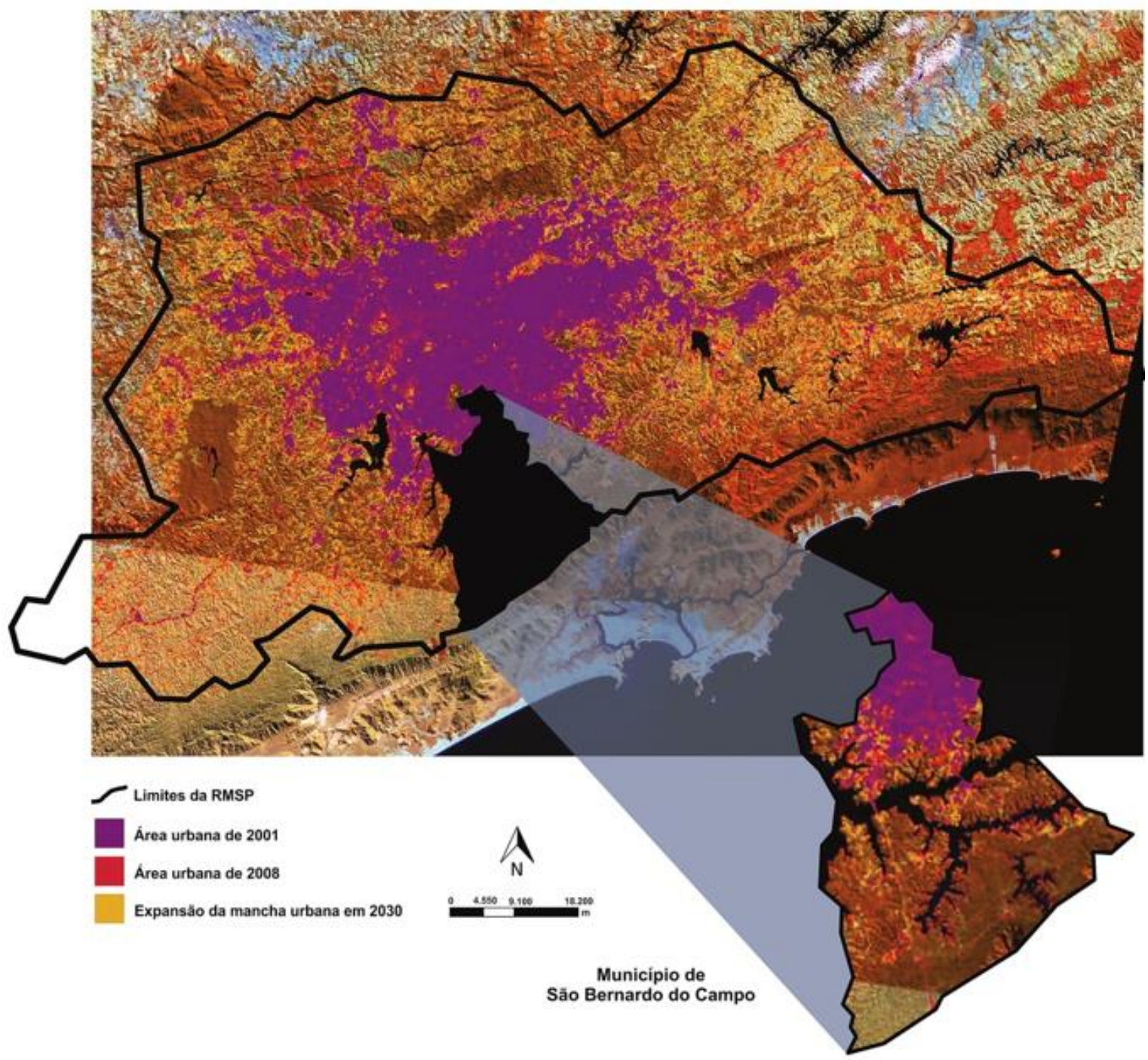

Fonte: Imagem de satélite Landsat 7 ETM+ (orbita. 219-076, resolução 30x30m). (NOBRE, 2010, p. 20-21). Adaptada pela autora.

São Bernardo do Campo encontra-se inserido na sub-região sudeste da RMSP, é um dos sete municípios que integra à microrregião do $A B C D^{1}$, seu desempenho nos diversos setores se deve a concentração histórica de atividades industriais locais, além de ter uma porção considerável - 66 \% de seu território inserido em área de proteção ambiental - APP, com uma extensão territorial de 408,0 $\mathrm{km}^{2}$, conta com uma superfície de $76 \mathrm{~km}^{2}$ de espelho d' água, além de $30 \%$ de sua população ocupar áreas de proteção e recuperação aos mananciais da Represa Billings, APRM-B (AGUILAR, 2009).

\footnotetext{
${ }^{1}$ Microrregião do ABCD - Esta região, correspondente hoje às "Sete Cidades", constituía em 1889 a Villa de São Bernardo. Com o crescimento e desenvolvimento populacional, econômico e político da região ocorreram os vários desmembramentos e a emancipação dos municípios, o último deles em 1964. A antiga Villa de São Bernardo deu lugar aos municípios atuais, Santo André, São Bernardo do Campo, São Caetano do Sul, Diadema, Mauá, Ribeirão Pires e Rio Grande da Serra. Disponível em: http://www.chgabc.com.br/o-congresso.html. Acesso em 20 de nov.2014.
} 


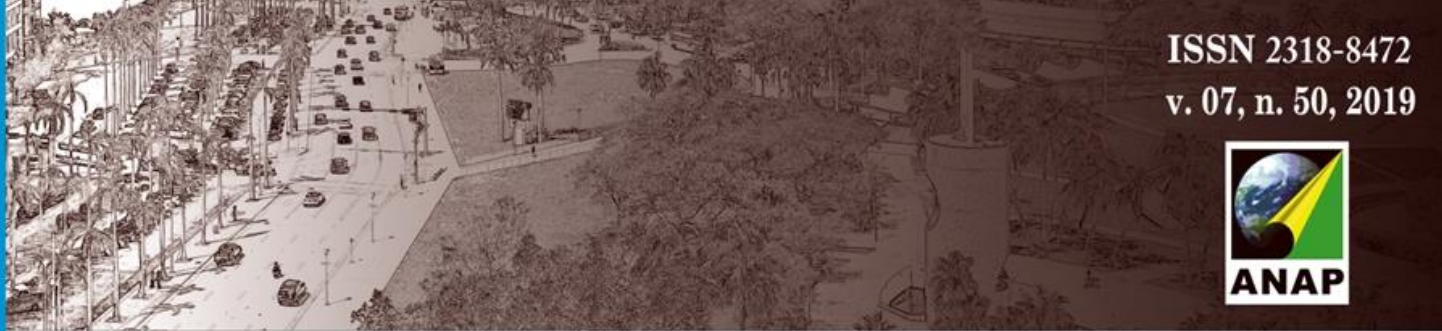

Revista Nacional de

Gerenciamento de Cidades

Toda essa conjunção de fatores, revelam sua relevância para a discussão da sustentabilidade ambiental urbana, tendo em vista que conformam um espaço permeado por uma série de externalidades, onde aspectos sociais, econômicos, políticos e ambientais devem ser compatibilizados. Desse modo, seu estudo traz para o contexto da discussão a política pública local e metropolitana, notadamente, ao buscar como referência empírica os programas e projetos voltados a proteção e recuperação das áreas de mananciais no âmbito da sub-bacia do reservatório Billings em São Bernardo do Campo.

\subsection{SÃO BERNARDO DO CAMPO: POLÍTICA URBANA E LEGISLAÇÃO DOS MANANCIAIS EM FACE DAS ÁREAS PROTEGIDAS.}

A partir de 2009, São Bernardo do Campo numa tentativa de equacionar as complexas demandas existentes em seu território, o poder público local inicia uma série de ações, visando implementar o Plano Local de Habitação de interesse Social no âmbito da Política Municipal de Habitação em consonância com a atual Política Nacional de Habitação (PNH) editada recentemente pelo Ministério das Cidades, assim como no âmbito da nova legislação de proteção aos mananciais.

Para tanto, diversos estudos tornaram-se essenciais, dentre eles, o mapeamento das áreas de risco, mapeamento dos assentamentos precários existentes, de forma a possibilitar um diagnóstico preciso da problemática habitacional, além da revisão do plano diretor à luz das recomendações técnicas da Lei Específica da Billings - Lei Estadual no 13.579/2009².

Dada sua importância ao saneamento ambiental das áreas de mananciais, para sua aplicação seria imprescindível a compatibilização dos planos diretores com suas diretrizes. Desse modo, esta normativa estabeleceu para os entes municipais inseridos na bacia hidrográfica da Billings, o compromisso de adequar suas normativas aos parâmetros urbanísticos e ambientais específicos a preservação, conservação e recuperação dos mananciais, como requisito fundamental aos processos de licenciamento de regularização de interesse do município.

Assim, após um exaustivo processo de discussões entre os diversos setores, em janeiro de 2015, a PMSBC finalizou a adequação de seu Plano Diretor as diretrizes estabelecidas na Lei Específica da Billings, a partir do qual, todos os empreendimentos inseridos em áreas de proteção e recuperação aos mananciais da Billings - para seu licenciamento deverão observar as diretrizes previstas na legislação estadual, em específico, em se tratando do parcelamento, uso e ocupação solo, além dos demais instrumentos anteriormente contemplados no plano diretor.

Com relação ao Plano Local de Habitação de Interesse Social, os estudos elaborados pela PMSBC (2011) foram essenciais para a revisão das áreas demarcadas como ZEIS no plano diretor e sua compatibilização com as áreas de recuperação ambiental (ARA) dentre os inúmeros instrumentos previstos na tentativa de equacionar seu elevado déficit habitacional. Neste contexto, merece ainda ser ressaltado a criação dos programas dedicados a Urbanização e Integração de Assentamentos

\footnotetext{
${ }^{2}$ Tendo em vista que a Lei específica da Billings, de modo diferenciado da Lei específica da Guarapiranga, a qual determina a remoção de assentamentos precários com a intenção de preservar as APP a lei da Billings, por sua vez, possibilita intervenção nessas localidades por meio dos Programas de Regularização de Interesse Social (PRIS).
} 


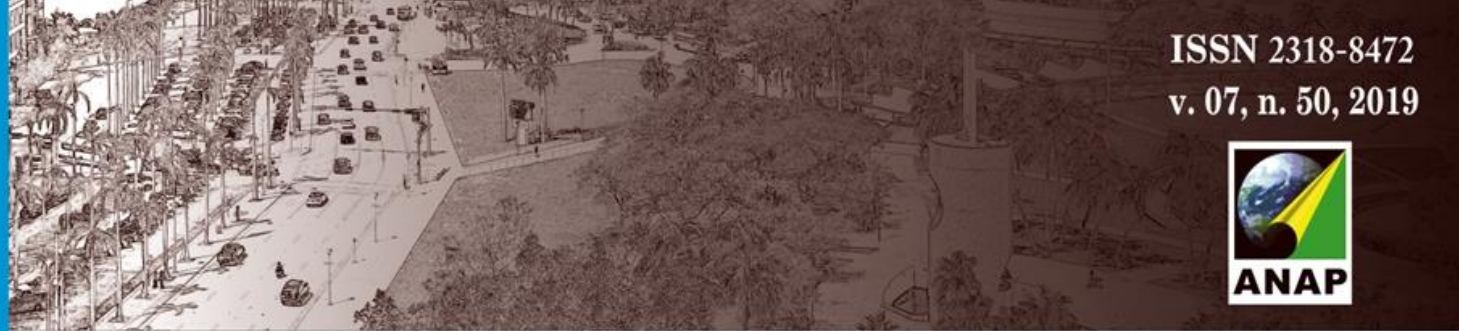

\section{Revista Nacional de} Gerenciamento de Cidades

Precários, além dos Programas de Regularização Fundiária, notadamente, por incidirem significativamente em áreas de proteção e recuperação aos mananciais. Com esta intenção, configuraram como medidas estratégicas os importantes mecanismos adotados pela Política Urbana e Habitacional de SBC, em especial, o PRIS (Programas de Recuperação de Interesse Social), e sua materialização nos projetos de intervenção e recuperação de áreas de preservação permanente (ALVIM at al, 2016).

Embora, a questão da proteção das áreas de preservação permanente tenha suas origens na legislação federal - reafirmada pelo atual Código Florestal (Lei 12.651/2012) enquanto uma das categorias dos espaços territoriais especialmente protegidos em áreas urbanizadas, foi também amparada pela legislação estadual em diversas normativas - desde a edição da LPM - Lei no $898^{3}$, de dezembro de 1975, quando foram definidas normas de restrição de uso e ocupação do solo, definindo como aquelas enquadradas de primeira categoria ou de maior restrição, art. 2ㅇ e posteriormente na lei 1.172/1976 4 , art. $2 \circ \S 1$, desta lei, além de ter sido amparada pela Lei Específica da Billings.

No âmbito desta normativa, sua proteção foi dada com o enquadramento nas áreas de restrição a ocupação - ARO, art. 4o, inciso II, alínea a, onde diversas tipologias foram protegidas, dentre elas, encontra-se as áreas de preservação permanente - APP (50m no entorno do reservatório Billings e dentro das unidades de conservação de proteção integral), além de, no art. 3o e inciso XIII, explicitar sua intenção em manter a integridade desses espaços, de forma a garantir a proteção, conservação, recuperação e preservação da vegetação e diversidade biológica (Lei 12.579/2009).

Em que pese, o aprimoramento das legislações visa entre outros aspectos, a proposição de políticas públicas, neste caso, as políticas urbanas e ambientais não deixam de ser instrumentos estratégicos no processo de desenvolvimento territorial de uma localidade, de uma região, por possibilitar sobretudo, o enfretamento dos diversos problemas de ordem socioambiental, em grande parte, permeados por intensa conflitualidade. Para os contextos, onde a consolidação de assentamentos precários em áreas protegidas é uma realidade, a intervenção urbana passa a exercer papel fundamental, por possibilitar uma articulação do projeto urbanístico às políticas habitacional e ambiental, sobretudo, quando abandonam as concepções de formato pontual para uma concepção ampliada, convergente e integradora das diversas dimensões afetas as áreas protegidas, em especial, as áreas de mananciais. A luz dos princípios que enunciam as recentes normativas urbanas e ambientais formuladas em âmbito municipal, aflora significativas possiblidades de inovação ao enfrentamento, sobretudo, para os projetos de intervenção em áreas de fragilidade ambiental, neste caso, as APRM da Billings. É com este olhar, que será brevemente analisado o PAC Alvarenga em São Bernardo do Campo.

\footnotetext{
${ }^{3}$ A Lei @ 898/1975, procurou disciplinar o uso do solo na área de proteção dos mananciais, cursos d’água, reservatórios e dentre outros, por meio de duas categorias de restrição. A primeira categoria criou uma área de restrição próxima ao manancial, onde apenas eram aceitos usos compatíveis com a proteção dos corpos d'água - artigo $8^{\circ}$ e $1^{\circ}$ parágrafo da referida lei, enquanto para a segunda categoria, foi estabelecido uma restrição menor e seu uso era determinado em conformidade com o interesse público.

${ }^{4}$ Estado editou a Lei $\mathrm{n}$ - 1.172/1976, com o objetivo de complementar a Lei ㅇ 898/1975, sendo que ambas foram regulamentadas pelo Decreto no 9.714/ 1977, prevendo e detalhando os padrões das faixas das áreas de proteção da rede hídrica do manancial, além de estabelecer um zoneamento baseado em índices de densidades de ocupação para as áreas da bacia hidrográfica.
} 


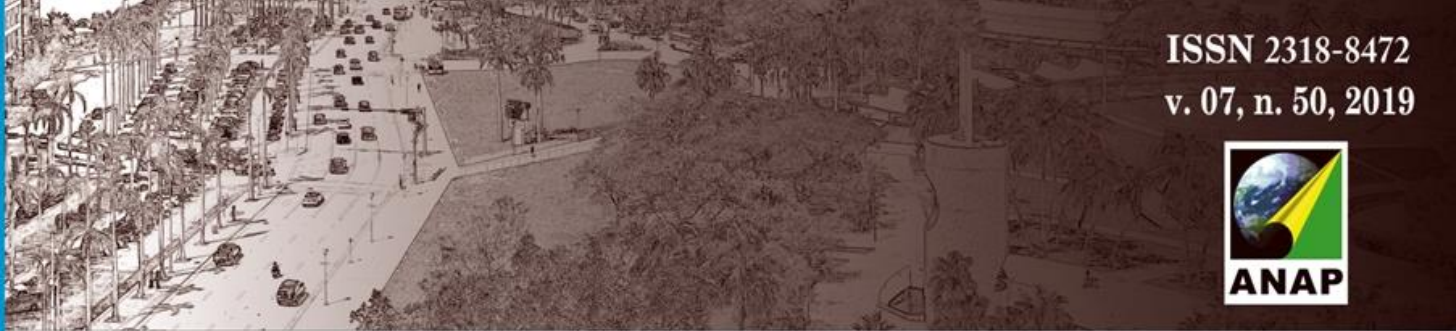

\section{Revista Nacional de} Gerenciamento de Cidades

necessidades e oportunidades de cada período que acompanha o próprio processo de urbanização do município (LIMA, 2014).

O arranjo físico dos assentamentos que integram o Bairro dos Alvarenga é bastante heterogêneo, na medida em que expressam a necessidade de melhorias de infraestrutura e adaptações as condições ambientais. Em direção a porção sul, no entorno da represa, a paisagem é permeada por espaços vegetados e ocupações mais recentes - caracterizadas como favelas, onde a provisão de rede de infraestrutura é quase inexistente (LIMA, 2014).

Em linha gerais, mesmo com diversas interferências que ocasionaram sua fragmentação espacial, ainda possui espaços intercortados por significativa hidrografia e massa arbórea nativa, componentes de grande importância para sua preservação e conservação.

Frente a essa breve exposição, o bairro ao longo de sua formação passou por várias intervenções, ainda que tenham ocorrido em caráter paliativo e pontual, o que evidenciavam já em 2005 a necessidade de uma atuação mais concreta e eficaz em resposta aos problemas existentes no local. Todos esses fatos justificam sua escolha como uma das primeiras localidades para a qual o poder público tentou buscar novas alternativas voltadas a urbanização de seus assentamentos.

Com essa intenção foi formatado o projeto denominado PAC Alvarenga pelo consórcio Habitat, iniciado em 2005, a partir de recursos provenientes do PAT PROSANEAR ${ }^{5}$, concebido para implementação de obras de saneamento em áreas favelizadas inseridas em APRM-B - Jardim Ipê, Sítio Bom Jesus, Alvarenga Peixoto e Divinéia - Pantanal I e II. As dimensões da precariedade somadas a densidade demográfica de cada núcleo - muitos as margens de cursos d'água, evidenciavam que intervenção urbanística a ser implementada deveria integrar ações de saneamento, habitação e implantação de espaços públicos por meio de áreas verdes e parques. Porém, em razão de sua elaboração anteceder a edição da Lei da Billings (Lei 13.579/2009), o projeto não se enquadrava em seus parâmetros técnicos, o que foi realizado somente após sua aprovação em 2009, tanto para adequá-lo as novas diretrizes determinadas pela nova lei, como para captar recursos do PAC, possibilitando seu início em março de 2010 (FERRARA, 2011).

Em virtude de tais aspectos, se fez necessário revisar e adequar a proposta inicial em conformidade com os critérios de enquadramento à formatação compreendida como "urbanização integrada" ${ }^{6}$, além de atender as diretrizes previstas no PRIS. Entretanto, todos esses cuidados não foram suficientes para garantir uma análise única, tanto que o processo de licenciamento se deu de forma fragmentada, implicando não apenas em fases diferenciadas de aprovação, mas também na execução das obras, incidindo principalmente na dificuldade de avaliar seus resultados, em específico, aqueles relacionados aos benefícios ambientais.

\footnotetext{
${ }^{5}$ PAT- PROSANEAR- Foi criado no ano de 2000, por meio de uma parceria entre o governo federal e o BIRD (Banco Internacional para Reconstrução e Desenvolvimento), o projeto de Assistência Técnica (PAT) ao PROSANEAR, tem por finalidade primordial a recuperação ambiental de áreas degradadas ocupadas por segmentos de menor renda, através da elaboração e implantação de projetos de saneamento integrado.

${ }^{6}$ Urbanização Integrada - O conceito de urbanização integrada consta da Política Nacional de Habitação. Trata de uma diretriz de política pública para promoção de ações de melhoria das condições de habitabilidade de populações residentes em assentamentos precários. Seu objetivo é reduzir os riscos socioambientais que esses loteamentos irregulares impõem a seus moradores e integrar a região ao tecido urbano da cidade. Disponível em: http://infraestruturaurbana.pini.com.br/solucoes-tecnicas/27/artigo288428-1.aspx. Acesso em abril de 2016.
} 


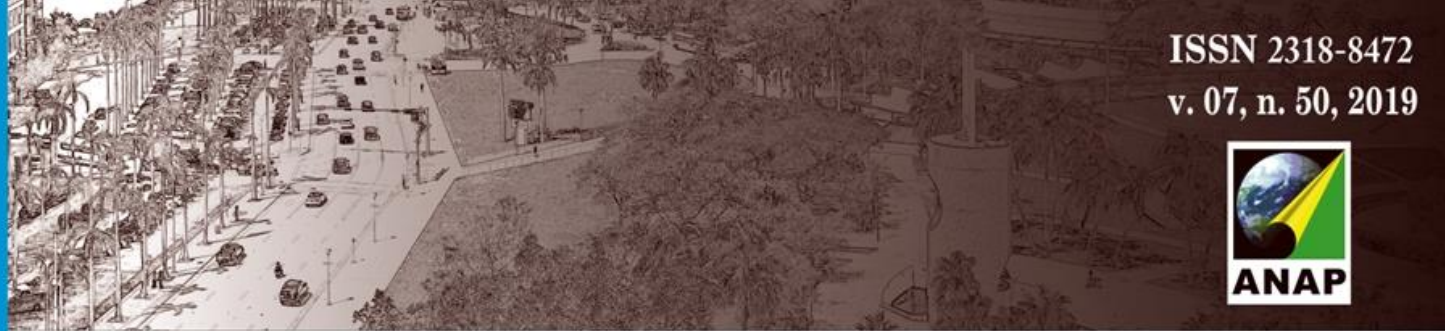

Revista Nacional de

Gerenciamento de Cidades

Ao considerar as demandas locais, sobretudo, pela necessidade de remoção de famílias em áreas de risco, assim como a identificação de áreas necessárias à instalação de redes de infraestrutura, o projeto implantado em 2010, ao considerar 2.514 imóveis cadastrados, conseguiu consolidar 610 unidades, para as quais foram realizadas adequações de infraestrutura e regularização, reassentou 878 famílias em novas unidades construídas no mesmo local, assim como remanejou 1026 famílias no Conjunto Habitacional Três Marias, localizado fora da área de proteção aos mananciais.

No que se refere as soluções de arquitetura apresentadas no âmbito do projeto de intervenção, tanto para as tipologias habitacionais, como as soluções de engenharia para as obras de saneamento, todas foram orientadas por uma abordagem tradicional.

Em sua primeira etapa, o núcleo Bom Jesus recebeu obras de saneamento ambiental, implantação das unidades habitacionais, canalização do córrego e implantação do parque linear em seu entorno, além da consolidação de habitações existentes. Na segunda etapa, foi contemplado o núcleo Divinéia Pantanal I e II, com execução das mesmas obras. Para sua terceira etapa, foram executadas diversas ações no Jardim Ipê, onde foram removidas 679 moradias e reassentadas também no Conjunto Habitacional, liberando o espaço para implantação de uma ampla área verde com parque linear. Para finalizar, na quarta etapa, foi possível a consolidação de um maior número de unidades, em contrapartida, uma proporção menor de espaços públicos.

Embora a PMSBC, tenha concluído diversas intervenções (Jardim Colina, Jardim Esmeralda, Parque Bandeirantes, Silvina, Silvina Oleoduto), o PAC Alvarenga ainda não foi integralmente concluído, principalmente pelas obras de saneamento não terem sido executadas na íntegra, o que torna ainda mais complexo realizar uma análise relacionada as intervenções já implantadas. No entanto, a SEHABSBC com o intuito de demonstrar para o órgão licenciador - CETESB os efeitos positivos relacionados aos aspectos ambientais, empregou indicadores que apontam de forma ilustrativa os resultados obtidos com as intervenções, associando-os aos valores da sustentabilidade.

\section{CONSIDERAÇÕES FINAIS}

É notório nesta região a conexão existente entre o acelerado processo de industrialização, a urbanização desordenada e o aumento da concentração populacional verificados ao longo dos anos, que por muito tempo permaneceram destituídas de ações adequadas de planejamento e ordenamento territorial, as quais contribuíram para a intensificação dos quadros de desigualdades sócio espaciais sustentados por um padrão de exploração e dilapidação de usos e degradação dos ecossistemas.

Ao tratar, em específico de áreas de preservação permanente em áreas de proteção aos mananciais, a questão é em si ainda mais complexa, não somente pela complexidade das leis que garantem sua tutela, mas essencialmente pela ausência de leituras mais aprofundada da realidade a ser recuperada, em que a compreensão do conceito das áreas de preservação permanente (APP), envolve em sua essência o reconhecimento de suas peculiaridades geofísicas, as quais transcendem as normativas jurídicas para alcançar as leis naturais - inerentes a sua gênese. 


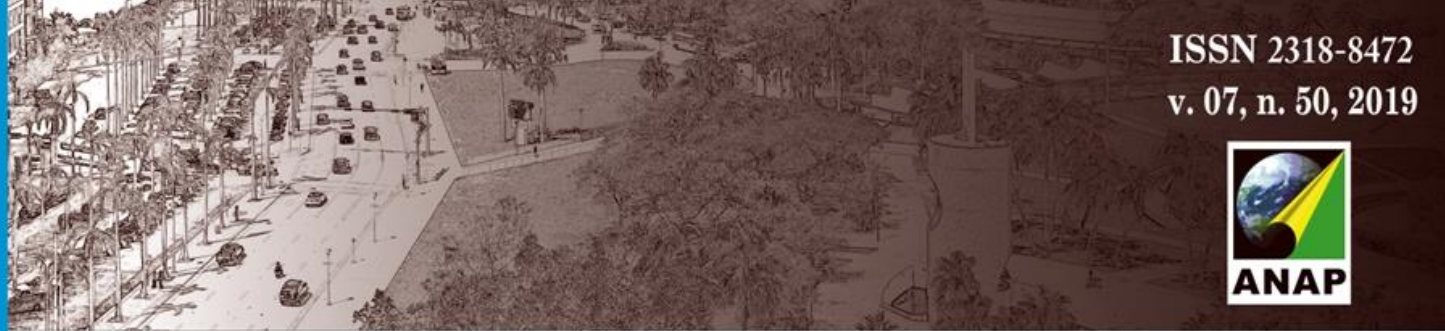

Revista Nacional de Gerenciamento de Cidades

Sob tais aspectos, compreender sua constituição física, a configuração - a geometria dos corpos d'água, as condições geológicas de seu relevo, além dos usos e ocupação de seu entorno, dentre outros aspectos são fundamentais para alcançar e aplicar os princípios de sustentabilidade, enquanto condição necessária a resiliência do suporte físico, do tecido social, assim como do ecossistema como um todo.

Neste contexto a emergência de um arranjo normativo abarcando as questões urbanas e ambientais sob um olhar sistêmico, configuram enormes possibilidades de respostas aos atuais quadros de adversidades que integram as paisagens específicas às áreas de proteção e recuperação aos mananciais. Embora, as práticas sejam ainda muito recentes, com base nos projetos elaborados no âmbito do PAC Alvarenga, se registre significativas melhorias, essas foram maiores em relação as questões sociais e urbanas, se comparadas aos benefícios ambientais advindos de sua implementação. Todavia, é preciso reconhecer a grande complexidade que envolve a implementação de ações dessa natureza, sobretudo em áreas onde há sobreposição de normas, valores, além de interferências de ordens várias, para as quais tornam-se imprescindíveis uma compreensão ampliada relacionada aos diversos aspectos envolvidos, dentre eles, são ressaltados:

1. As normativas urbanas ambientais apresentam significativos avanços para o tratamento das questões que afetam os ambientes em áreas de proteção e recuperação aos mananciais, porém, essas ainda são insuficientes frente as inúmeras divergências que apresentam, em especial, aquelas relativas ao uso e ocupação do solo e a preservação dos bens ambientais.

2. Ainda, que as recentes revisões tenham incorporado tanto no Plano Diretor, como no Plano Local de Habitação de Interesse Social, os princípios de sustentabilidade, ao enunciar sua importância em assegurar o direito à cidade, a garantia de uma moradia digna, a preservação dos bens ambientais, com notoriedade, para a proteção e recuperação das áreas de mananciais, elegendo ações estratégicas para sua efetividade, a exemplo das intervenções urbanas em APRM, estas em suas componentes devem necessariamente aplicar desde seus conceitos fundantes até as tecnologias que possam garantir sua concretização. Em específico, as soluções voltadas ao saneamento ambiental, por estarem inseridas em um território com fragilidades ambientais acentuadas, tornam-se prementes que sejam praticadas as ferramentas disponíveis na infraestrutura verde, onde as soluções de engenharia tanto para rede de drenagem, de esgotamento sanitário, tentem minimizar os impactos ao meio natural e social.

3. Sem a pretensão de esgotar a questão, merece ser destacado, que Lei Específica Billings traz em seu cerne, diversos instrumentos importantes para a preservação e recuperação das áreas de mananciais, dentre eles, destaca-se o Pagamento por Serviços Ambientais, entretanto não tem sido valorizado ou percebido suas potencialidades. 


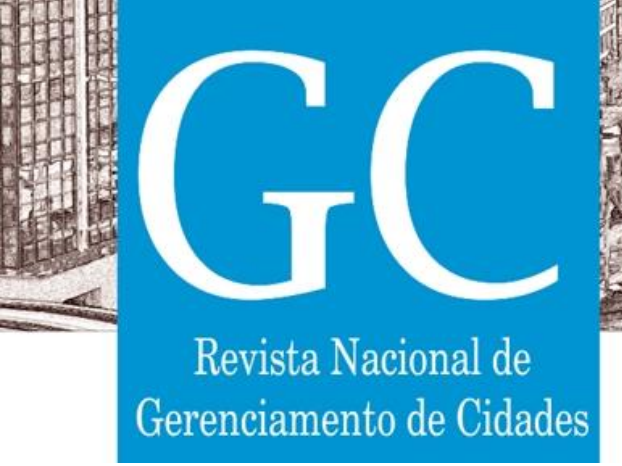

Tendo em vista que processos que promovem a ocupação do espaço nesses ambientes, tem uma velocidade e proporção muito acima da capacidade de resposta do estado, talvez a maior questão a seu enfretamento esteja em reconhecer que espaços ambientalmente protegidos, em função das suas especificidades, em especial, ao incorporar as áreas de preservação permanente torna-se imprescindível realizar uma leitura interdisciplinar com a finalidade de buscar uma compreensão aprofundada de suas interfaces, afim garantir maior efetividade as ações governamentais tanto na escala temporal como espacial. Para finalizar, torna-se obrigatório o entendimento da importância da contribuição de determinados processos, notadamente, aqueles voltados a promoção da sustentabilidade, os quais se configuram como um fator de desenvolvimento, e não o seu oposto. De modo a conduzir a um processo consistente de desenvolvimento, elevando a níveis de equidade e justiça social por meio da implementação estratégica de políticas públicas inovadoras, onde seja possível compatibilizar as componentes naturais e físicas ao projeto urbano, em especial, resgatando a prestação dos serviços ecossistêmicos essenciais, não somente à sustentabilidade, mas também, um caminho necessário a resiliência dos espaços protegidos.

\section{NOTA}

Este artigo é parte de uma pesquisa em fase de conclusão/ tese de doutorado, desenvolvida desde 2012 no âmbito do Programa de Pós-Graduação em Arquitetura e Urbanismo da Universidade Presbiteriana Mackenzie, sob a orientação da Prof.a Dra Angélica A. T. Benatti Alvim.

\section{REFERENCIAL}

ALVIM, A. T. B. Assentamentos irregulares e proteção ambiental: impasses e desafios da nova legislação estadual de proteção e recuperação dos mananciais na Região Metropolitana de São Paulo. In: BOGUS, L. M. M. et al. (orgs.). Reconversão e reinserção urbana de loteamento de gênese ilegal: análise comparativa Brasil-Portugal. São Paulo, Educ, 2010.

ALVIM, A. T. B et al. Das políticas públicas ambientais e urbanas às intervenções: os casos das Sub-Bacias Guarapiranga e Billings no Alto Tietê. Relatório de pesquisa. São Paulo, Faculdade de Arquitetura e Urbanismo, Universidade de São Paulo/Fundo Mackpesquisa, 2014

ALVIM, Angélica Tanus Benatti; KATO, Vólia Regina Costa; ROSIN, Jeane Rombi de Godoy. A urgência das águas: intervenções urbanas em áreas de mananciais. Cad. Metrop., São Paulo,v. 17, n. 33, p. 83-107, Maio de 2015. Disponível em: http://www.scielo.br/scielo.php?script=sci arttext\&pid=\$2236-99962015000100083\&lng=en\&nrm=iso . Acesso em 18 abril, 2016.

ALVIM. Angélica. T. B. A Contribuição do Comitê da Bacia do Alto Tietê à gestão da Bacia Metropolitana, 1994-2001. Tese (Doutorado em Arquitetura e Urbanismo). Faculdade de Arquitetura e Urbanismo. Universidade de São Paulo, FAUUSP. São Paulo, 2003.

ANCONA, Ana Lúcia. Direito ambiental, direito de quem? Políticas Públicas do Meio Ambiente na Metrópole Paulista. Tese (Doutorado em Arquitetura e Urbanismo). Faculdade de Arquitetura e Urbanismo. Universidade de São Paulo, FAUUSP. São Paulo, 2002. 


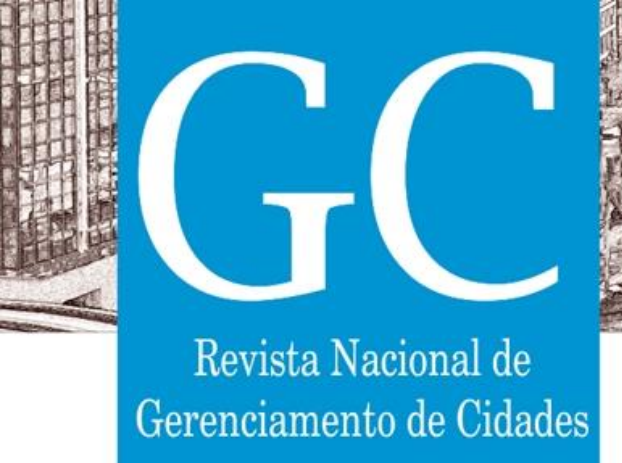

AGUILAR, C.B.D. A produção do espaço urbano no Trecho Sul do Rodoanel em São Bernardo do Campo (SP): impasse e perspectivas. Dissertação de Mestrado, Universidade Presbiteriana MacKenzie. São Paulo, 2009. BRASIL. Lei no 12.651, de 25 de maio de 2012. Institui o novo Código Florestal. Disponível em: < http://www.planalto.gov.br/ccivil_03/_ato2011-2014/2012/lei/l12651.htm>. Acesso em: 24 mai. 2016.

. Constituição (1988). Constituição da República Federativa do Brasil: promulgada em 5 de outubro de 1988. Lei Federal no 4.771, de 15 de setembro de 1965. Institui o novo Código Florestal. Brasília, 1965.

Lei Federal no 10.257, de 10 de julho de 2001. Estatuto da Cidade. DOU 11.07.2001, ret. DOU 17.07.2001.

. Lei Federal no 12.651, de 25 de maio de 2012.Dispõe sobre a proteção da vegetação nativa; altera as Leis nos 6.938, de 31 de agosto de 1981, 9.393, de 19 de dezembro de 1996, e 11.428, de 22 de dezembro de 2006; revoga as Leis nos 4.771, de 15 de setembro de 1965, e 7.754, de 14 de abril de 1989, e a Medida Provisória no 2.166-67, de 24 de agosto de 2001; e dá outras providências. Brasília, 2012.

FERRARA, Luciana Nicolau. Urbanização da natureza: da autoprovisão de infraestruturas aos projetos de recuperação ambiental nos mananciais do sul da metrópole paulistana. Tese apresentada à Faculdade de Arquitetura e Urbanismo da Universidade de São Paulo, para obtenção de grau do título de Doutor em Arquitetura e Urbanismo, 2013.

IBGE. Instituto Brasileiro de Geografia e Estatística. Censo de 2010. Disponível em <http://www.censo2010.ibge.gov.br/sinopse/webservice/default.php?cod1=35\&cod2=355500\&cod3=35\&frm=urb_rur>. Acesso em 17 jul. 2013.

LIMA. Patrícia, Helen. BAIRRO dOS ALVARENGA: DO CAOS À SUSTENTABILIDADE. Revista LABVERDE $\mathrm{n}^{\circ} 8$ - Artigo $\mathrm{n}^{\circ} 03$, junho de 2014. Disponível em: http://www.revistas.usp.br/revistalabverde/article/viewFile/83547/86474. Acesso em junho de 2015.

NOBRE, C A.; YOUNG, A F.; SALDIVA, P; MARENGO, J A; NOBRE, A D.; ALVES Jr., S; da SILVA, G C M; Lombardo, M. Vulnerabilidades das Megacidades Brasileiras às Mudanças Climáticas: Região Metropolitana de São Paulo. Centro de Ciência do Sistema Terrestre do Instituto Nacional de Pesquisas Espaciais (INPE), Núcleo de Estudos de População da Universidade de Campinas (UNICAMP), Faculdade de Medicina da Universidade de São Paulo (USP), Instituto de Pesquisas Tecnológicas de São Paulo (IPT) e Universidade Estadual Paulista (UNESP - Rio Claro). Junho de 2010.

PLHIS-PMSBC. PRODUTO FINAL CONSOLIDADO / maio de 2012. Trabalho co-financiado pelo Ministério das Cidades através da CAIXA pelo contrato de repasse no: 0236.736-74/2008

PMSBC - PREFEITURA DO MUNICÍPIO DE SÃO BERNARDO DO CAMPO. Sumário de Dados 2012 - Ano Base: 2011. São Bernardo do Campo, 2011.

SÃO PAULO (Estado). Secretaria do Meio Ambiente / Coordenadoria de Educação Ambiental. Billings. São Paulo: SMA/CEA, 2010.

. Lei Estadual de Proteção aos Mananciais no 898/75. São Paulo, Assembleia Legislava, 1ㅇ/11/1975. (Já alterada pela Lei Estadual no 3.746/83).

. Lei Estadual no 1.172/76. Delimita as áreas de proteção relavas aos mananciais, cursos e reservatórios de água, a que se refere o artigo 20 da Lei Estadual no 898, 18 de dezembro de 1975, estabelece normas de restrição do uso do solo em tais áreas e dá providências correlatas. São Paulo, Assembleia Legislativa, 17/11/76.

Lei Estadual de Proteção aos Mananciais no 9866/97 - Uma nova política de Mananciais: Diretrizes e Normas para a Proteção e Recuperação das Bacias Hidrográficas dos Mananciais de interesse Regional do Estado de São Paulo. São Paulo, Assembleia Legislativa, 28/11/1997.

. Lei Estadual no 12.233. Define a Área de Proteção e Recuperação dos Mananciais da Bacia Hidrográfica do Guarapiranga, e dá outras providências correlatas. São Paulo, Assembleia Legislativa, 16/01/2006. 
